\title{
CARACTERIZAÇÃo DA HISTÓRIA PARA O ENSINO DO SISTEMA DE NUMERAÇÃO DECIMAL EM TESES E DISSERTAÇÕES
}

\author{
CHARACTERIZATION OF THE HISTORY FOR TEACHING THE \\ DECIMAL NUMBER SYSTEM IN THESIS AND DISSERTATIONS
}

Lucas Silva Pires ${ }^{1}$

\section{Resumo}

Este artigo resulta de uma investigação que está vinculada a dois projetos de pesquisa financiados pelo Conselho Nacional de Desenvolvimento Científico e Tecnológico (CNPq). Trata-se de um estudo documental bibliográfico na modalidade pesquisa sobre as produções brasileiras em História da Matemática. O nosso objetivo foi caracterizar as propostas didáticas tratadas em teses e dissertações da história para o ensino do sistema de numeração decimal para os anos iniciais do Ensino Fundamental. Busca-se responder a seguinte questão: Quais teses e dissertações da História da Matemática podem contribuir no ensino de sistema de numeração decimal para os anos iniciais do Ensino Fundamental? O estudo está fundamentado em Mendes (2014), que identificou três tendências nas pesquisas em História da Matemática. 1) História para o Ensino da Matemática; 2) História e Epistemologia da Matemática; 3) História da Educação Matemática. O corpus investigativo compõe-se de teses e dissertações defendidas em programas de Pós-Graduação $s$ tricto sensu do Brasil, as quais estão publicadas no Portal de Coordenação de Aperfeiçoamento de Pessoal de Nível Superior (CAPES) e em Biblioteca Digital Brasileira de Teses e Dissertações (BDTD). Os resultados indicaram a existência de teses e dissertações com potencialidade didática, as quais podem servir como ferramental didático-pedagógico aos professores que lecionam nos anos iniciais do Ensino Fundamental.

Palavras-chave: História da Matemática. História para o Ensino da Matemática. Sistema de Numeração Decimal. Anos Iniciais.

\footnotetext{
${ }^{1}$ Mestre em Educação em Ciências e Matemáticas pela Universidade Federal do Pará (UFPA): Membro do Grupo de Pesquisa sobre Práticas Socioculturais e Educação Matemática (GPSEM). Membro do Centro Brasileiro de Referência em Pesquisa sobre História da Matemática (CREPHIMat)

E-mail:lucas.silvapires.10@gmail.com
} 


\section{Considerações Iniciais}

Nas últimas três décadas as produções relativas a dissertações e teses em História da Matemática dos programas de Pós-Graduação stricto sensu do Brasil têm tido um crescimento significativo. Pesquisadores e vários estudiosos têm dedicado seus estudos na difusão e disseminação de produções da História da Matemática. Esse movimento tem contribuído para a constituição da área que tem ganhando um escopo importante na comunidade científica. Tendo em vista a vasta disseminação e difusão das pesquisas em torno dessa área, direcionamos nosso estudo centrado nas produções que trataram da história para o ensino do sistema de numeração decimal para os anos iniciais, cujo objetivo foi caracterizar as propostas didáticas tratadas em teses e dissertações da história para o ensino de sistema de numeração decimal para os anos iniciais do Ensino Fundamental.

O artigo resulta de dois projetos "guarda-chuvas" financiados pelo Conselho Nacional de Desenvolvimento Científico e Tecnológico (CNPq) ${ }^{2}$. Os projetos dão continuidade às pesquisas realizadas nos últimos dez anos por Mendes (2014) em especial o projeto "Cartografia da Produção em História da Matemática no Brasil: um estudo centrado nas teses e dissertações defendidas entre 1990 - 2010", cujo propósito consistiu em

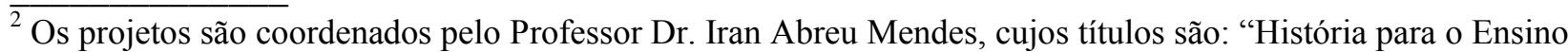
de Matemática na Formação de Professores e na Educação Básica: uma análise da produção brasileira entre 1990 e 2018 " e "Uma história das pesquisas em História da Matemática no Brasil: produções, disseminações e contribuições à Formação de Professores de Matemática". O objetivo dos projetos centrou-se na investigação de quais modos e sentidos as modalidades de abordagem histórica propostas para o uso didático nas aulas de Matemática são produzidas por pesquisadores e educadores e até que ponto são aplicadas pelos professores de Matemática em suas aulas nas escolas públicas na Educação Básica (MENDES, 2018).
} 
Caracterização da História para o ensino do sistema de numeração decimal em teses e dissertações

cartografar teses e dissertações em História da Matemática no Brasil, defendidas nessas três décadas, para prosseguir com as investigações já desenvolvidas por Mendes, ao realizar uma radiografia sobre os trabalhos publicados nos Anais dos Seminários Nacionais de História da Matemática, tendo sido apresentados, no ano de 2008, os primeiros resultados da pesquisa, quando o referido professor atuou como um dos Coordenadores no Seminário Nacional de História da Ciência e Tecnologia (SNHCT), dando, na sequência, continuidade às informações apresentadas em um artigo publicado por Sad (2005) nos Anais do Seminário Nacional de História da Matemática ocorrido na Universidade de Brasília (UnB) em 2005 (MENDES, 2015).

Aproxima-se, portanto, de um estudo documental bibliográfico na modalidade pesquisa sobre as produções relativas à História para o Ensino do Sistema de Numeração Decimal (SND) aos Anos Iniciais. É nesse sentido que buscamos resposta à seguinte questão: Quais teses e dissertações da História da Matemática podem contribuir no ensino de sistema de numeração decimal para os anos iniciais?

\section{Sobre a História para o Ensino da Matemática}

Ao longo das últimas três décadas (1990-2020), pesquisas em História da Matemática têm crescido substancialmente. As mais diversas pesquisas de ordem teórica e epistemológica nesse campo têm reverberado muitas discussões a respeito do ensino de Matemática nos mais diversos niveis de ensino. Em virtude desse movimento, nas pesquisas realizadas por Mendes (2014) foram identificadas três tendências em História da Matemática (figura 1). 


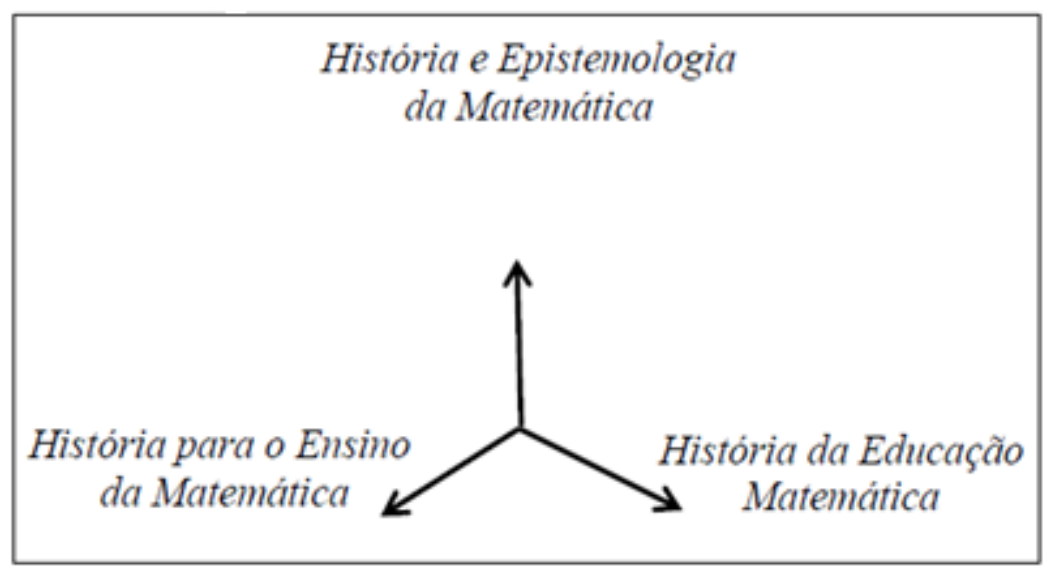

Figura 1: Tendências da História da Matemática Fonte: Mendes (2018, p. 46)

De acordo com Pires e Mendes (2020), as produções que foram classificadas em três tendências da História da Matemática possuem as seguintes características:

História e Epistemologia da Matemática (HEpM) - foram as pesquisas que se caracterizaram pelo desenvolvimento epistemológico de uma teoria ou de um conceito matemático e do desenvolvimento de um tema específico da Matemática, bem como vida e obras de matemáticos, sobre as ideias matemáticas produzidas ao longo da história da humanidade.

A tendência História para o Ensino da Matemática (HEnM) - foram as pesquisas que se caracterizaram pela preocupação com fins pedagógicos como elaboração de materiais didáticos para ensinar Matemática, usando fragmentos da História da Matemática, os quais podem ser utilizados, tanto na elaboração de materiais didáticos para dar subsídios aos professores em sala de aula, como também, 
Caracterização da História para o ensino do sistema de numeração decimal em teses e dissertações

materiais que trataram de orientar o professor sobre a forma como utilizar fontes históricas para ensinar matemática, bem como para a formação de professores que ensinam matemática em diversos níveis de ensino (BARROS e MENDES, 2017, p. 140).

A tendência História da Educação Matemática (HEdM) - foram as pesquisas que trataram de biografias de matemáticos, tanto dos antigos, como dos atuais, da história de instituições, história e memória, história oral, história de cursos, entre outros aspectos. Para Mendes (2015; 2019), existem onze subáreas que caracterizam essa tendência: 1. Investigação sobre a vida de matemáticos ou educadores; 2. Investigação sobre a evolução de algum conceito ou teoria; 3. Investigação sobre uma área de conhecimento; 4. Investigação sobre história de instituições; 5 . Investigação sobre o contexto cultural de uma criação; 6. Investigação sobre uma época determinada; 7. Investigação sobre um grupo específico; 8. Investigação sobre as relações da Matemática com outras áreas do conhecimento; 9. Investigação sobre as aplicações da História da Matemática; 10. Investigação sobre livros didáticos; 11 . Investigação sobre o desenvolvimento de produções acerca da História da Matemática.

Em se tratando especificamente da tendência HEnM, esta vem se tornando um campo frutífero e se constituindo como lócus de pesquisas, visto que, com o desenvolvimento do estudo sobre as produções em História da Matemática, foram identificadas teses e dissertações com abordagens diversas, como, testagem e método criado por matemático para ensinar Matemática; aplicação de fontes históricas no ensino de Matemática; relação da Matemática com outras áreas de conhecimento; ensino de Matemática em livros didáticos; desenvolvimento de conceitos e atividades históricas; atividades e artefatos históricos no ensino de Matemática; 
Caracterização da História para o ensino do sistema de numeração decimal em teses e dissertações

atividade didática concreta para a sala de aula; proposta de ensino em diferentes épocas; uso de conceitos matemáticos na prática do professor; propostas pedagógicas para a formação de professores; orientação didática sobre o uso de fontes históricas.

\section{Sobre os Procedimentos Metodológicos}

Para a operacionalização deste estudo, realizamos um levantamento sobre as produções brasileiras em História da Matemática no interstício de 1990 a 2018. Nesse sentido, para fazer o download de teses e dissertações, foi necessário a realização de leituras de seus resumos, introduções e conclusões, a fim de verificar a pertinência em História da Matemática e, quando necessário, foi feito a leitura de todo o trabalho, com vistas a classificar cada trabalho nas tendências em História da Matemática. Foi criada uma planilha, a qual foi preenchida com base nos seguintes classificadores: nome do autor, título do trabalho, instituição, programa de Pós-Graduação, nível do trabalho, ano de publicação, tendência identificada, subárea, conteúdo e nível de ensino.

O levantamento foi realizado no portal de Coordenação de Aperfeiçoamento de Pessoal de Nivel Superior (CAPES) e na Biblioteca Digital Brasileira de Teses e Dissertações (BDTD). Quando não estavam disponíveis em domínio público, houve a necessidade de visitar vários portais de bibliotecas virtuais das Universidades brasileiras de diversos programas brasileiros de Pós-Graduação stricto sensu.

Para isso, foram adotas várias palavras-chave no campo de busca com as aspas e sem letras maiúsculas para melhor refinar o resultado e atingir nosso objetivo. As palavras-chave foram as relacionadas à História da Matemática, conforme segue: "história da matemática", "história no 
Caracterização da História para o ensino do sistema de numeração decimal em teses e dissertações

ensino de matemática", "história pela matemática", "história para o ensino de matemática", "história da educação matemática", "história do ensino de matemática", "história na educação matemática", "história e pedagogia da matemática", "história da aritmética", "história da álgebra", "história da geometria", "história da trigonometria", "história do cálculo", "história da estatística", "história da probabilidade" e "história da lógica".

Ao digitarmos as palavras-chave no campo de busca, eram apresentados os títulos, o autor, o programa de Pós-Graduação e o nível (Mestrado ou Doutorado). Assim, realizávamos o download do que estava disponivel no momento. Para o que não estava disponivel, utilizávamos as informações obtidas para visitar inúmeras bibliotecas virtuais, a fim de encontrar o trabalho em arquivo que pudesse ser baixado da internet. Quando o problema persistia, entrávamos em contado com o autor, solicitando o arquivo/trabalho. Em muitos casos, obtivemos êxito e pudemos compor o rol de teses e dissertações em História da Matemática.

Houve toda uma problemática repleta de tratativas durante o levantamento, com algumas dificuldades, pois, embora usássemos as palavras-chave com letras minúsculas e com aspas para refinar a busca, a plataforma da CAPES não apresentava um número preciso, o que nos parece ser um problema de ordem técnica daquela base de dados. Mesmo assim, persistimos na busca e identificamos 388 teses e dissertações. Esse total foi agregado ao que havia sido identificado e classificado na pesquisa realizada por Mendes $(2014 ; 2015)$, conforme já mencionamos.

Diante do exposto, encontram-se relacionadas na planilha, devidamente organizadas por arquivos, classificadas por tendências em História da Matemática e materializadas no Centro Brasileiro de Referência 
Caracterização da História para o ensino do sistema de numeração decimal em teses e dissertações

em Pesquisa sobre História da Matemática (CREPHIMat) ${ }^{3} 698$ teses e dissertações em História da Matemática, sendo 363 dissertações de Mestrado Acadêmico, 128 dissertações de Mestrado Profissional e 207 teses de Doutorado. Além desses, 55 trabalhos não puderam ser baixados e, caso os considerássemos, o total geral seria de 753 teses e dissertações identificadas em História da Matemática, produzidas no Brasil durante as últimas três décadas.

Somente após essa fase, focamos em 5 Teses de Doutorado, 2 Dissertações de Mestrado Acadêmico e 2 Dissertações de Mestrado Profissional que trataram da história para o ensino do SND. Lemos todos os resumos, as palavras-chave, as introduções, bem como as fontes históricas que foram utilizadas na elaboração de atividades, para a identificação, classificação e caracterização desses trabalhos. Para isso, com base nos estudos relativo a matriz paradigmatica de Gamboa (2012) criamos um instrumento de análise com elementos que nos subsidiaram durante a caracterização de teses e dissertaçãoes que trataram da história para o ensino do SND (quadro 1).

Quadro 1 - Instrumento para análise das pesquisas em história para o ensino do SDN

Título: Deve constar o título do trabalho analisado

Autor: Deve ser evidenciado o responsável pela autoria do trabalho elaborado.

Ano: Deve constar o ano em que o trabalho foi elaborado.

Conceito epistemológico que sustenta a elaboração de atividades: Deve estar em sintonia com o objeto de estudo que é abordado no trabalho.

Tipo de história tratada: Para que o trabalho seja potencialmente elaborado como recurso didático a ser utilizado pelo professor, deve conter os três tipos de história (história formativa, história informativa e/ou história utilitária).

3 O CREPHIMat é um centro virtual idealizado e criado pelo professor Iran Abreu Mendes a partir dos seus projetos de pesquisa sobre o tema. Tal Centro disponibiliza produções científicas sobre História da Matemática do Brasil, dentre outras informações e materiais enquadrados nessa temática. 
Caracterização da História para o ensino do sistema de numeração decimal em teses e dissertações

Fontes históricas tratadas do trabalho: Deve ser analisado como as fontes históricas são tratadas, tanto na elaboração do trabalho como na elaboração de atividades.

Abordagem interdisciplinar: A história problematizada deve ocorrer a integração entre outras áreas de conhecimento e integração entre a história do conteúdo e o conteúdo escolar com fins didáticos.

Problematização interativo-dialógica: Deve haver interação dialógica e discussão das atividades que estimula a interação entre alunos, alunos e professores, professores e alunos para a transformação histórica dos temas matemáticos sob estudo.

Abordagem cognitiva motivacional: A proposta didática a partir do uso de fontes históricas deve ser provocadora para despertar o estímulo e a curiosidade do aluno e, consequentemente, despertar seu pensamento cognitivo.

Pensamento crítico: A proposta didática apresentada no trabalho deve ter potencial para desempenhar o pensamento crítico do aluno, de modo que perceba as relações de poder associados aos diferentes momentos históricos das ideias matemáticas nas práticas socioculturais e a relação dialógica entre as práticas sociais do passado e presente para desempenhar seu espírito crítico.

Relação dialógica entre passado e presente para a motivação criativa: Deve estar claro no trabalho, a relação entre as ideias matemáticas desenvolvidas no passado com a matemática do presente para despertar a curiosidade pela investigação histórica e, consequentemente ampliar o conhecimento do aluno.

Aspectos tratados sobre o objeto de estudo: Deve ser analisado o potencial pedagógico a partir do objeto de estudo tratado no trabalho.

Contribuições do sistema de numeração decimal para o ensino de aritmética: Deve ser analisado o potencial didático que as atividades desenvolvidas no trabalho sobre sistema de numeração decimal têm para o ensino de aritmética.

Problemas investigatórios: Deve ser uma história que põe problemas, isto é, que parte de problemas que se manifesta a relação entre práticas pedagógicas investigativa do passadopresente, que se preocupa com os estudantes do presente, quanto futuros professores de Matemática, não necessariamente nos historiadores de ofício, para isso, as atividades devem ser investigativas.

Fonte: Pires (2019, p. 198) 
Caracterização da História para o ensino do sistema de numeração decimal em teses e dissertações

O instrumento composto por alguns elementos para a análise das pesquisas que se referiram sobre o conteúdo sistema de numeração decimal subsidia-nos a entender até que ponto os trabalhos que foram elaborados servem para ensinar o conteúdo especificado, pois, para percebermos as pesquisas potencialmente elaboradas para subsidiar os professores em sua prática, o conceito epistemológico deve estar em sintonia com o objeto de estudo que é abordado no trabalho, haja vista que existem pesquisas que os conceitos epistemológicos não correspondem ao objeto de estudo que é tratado no trabalho, podendo assim, causar efeitos contrários ao objetivo.

Assim, é necessária a verificação de como a história formativa, informativa e utilitária são exploradas para que o trabalho sirva pedagogicamente para subsidiar o professor em sua prática docente a partir do uso de fontes históricas adotadas na elaboração de atividades, pois, conforme afirma Miguel e Miorim (2008), para que a história seja pedagogicamente vetorizada, é necessário que haja problematização dessas fontes tratadas nos trabalhos, ou seja, a integração entre outras áreas de conhecimento e entre a história do conteúdo e o conteúdo de Matemática, neste caso, sistema de numeração decimal, bem como o modo como é organizado o trabalho para alcançar o objetivo proposto para que o professor compreenda o conteúdo apresentado para despertar a motivação e, consequentemente a aprendizagem no aluno.

É com base nesses aspectos que a proposta didática apresentada com base no uso de fontes históricas deve ser provocadora para despertar o estímulo e a curiosidade do aluno e, consequentemente, despertar o pensamento cognitivo a partir das fontes históricas tratadas no trabalho. Ao despertar seu pensamento cognitivo, passará a ter o pensamento crítico sobre as relações de poder associados aos diferentes momentos histó- 
Caracterização da História para o ensino do sistema de numeração decimal em teses e dissertações

ricos em contextos socioculturais, a respeito das ideias matemáticas e perceber a relação intrínseca entre o conhecimento matemático produzido no passado com o conhecimento matemático produzido no presente.

Para isso, é necessária uma análise mais rebuscada dos trabalhos que tratam do sistema de numeração decimal, para perceber as contribuições que o referido conteúdo tem para o ensino de matemática. Isso será possivel através dos elementos norteadores estabelecidos no instrumento para análise. Para além disso, as abordagens devem contribuir para a interação dialógica e discussão que estimula a interação entre alunos, alunos e professores, professores e alunos para a transformação histórica dos temas matemáticos sobre o estudo.

Para que isso ocorra, a proposta didática a partir do uso de fontes históricas deve ser provocadora para despertar o estímulo e a curiosidade do aluno e, consequentemente, despertar seu pensamento cognitivo e deve ter potencial para desempenhar o pensamento crítico do aluno, de modo que se perceba as relações de poder associados aos diferentes momentos históricos das ideias matemáticas nas práticas socioculturais e a relação dialógica entre as práticas sociais do passado e presente para desempenhar seu espírito crítico.

Através dos referidos elementos do instrumento de análise, realizamos a análise das dissertações e teses que apresentavam propostas didáticas concretas para o ensino de sistema de numeração decimal para os anos iniciais, como forma de sistematização das produções que servirá de fonte de estudo para outras investigações. 


\section{Sobre as teses e dissertações da História do Sistema de Numeração Decimal}

Ao empreendemos um estudo centrado em teses de Doutorado e dissertações de Mestrado Acadêmico e Profissional, referente à História de SND aos Anos Iniciais, as classificamos quantitativamente nas três tendências em História da Matemática, prosseguindo com uma descrição comentada a respeito do número de pesquisas desenvolvidas e classificadas em cada tendência (quadro 2).

Quadro 2 - Teses e Dissertações classificadas nas tendências em História da Matemática (1990-2018).

\begin{tabular}{|c|c|c|c|c|}
\hline \multirow{2}{*}{ Tendências } & \multicolumn{2}{|c|}{ Mestrado } & \multirow{2}{*}{ Doutorado } & Total \\
\cline { 2 - 5 } & Acadêmico & Profissional & & \\
\hline HEpM & 75 & 5 & 55 & 135 \\
\hline HEnM & 60 & 72 & 21 & 153 \\
\hline HEdM & 228 & 51 & 131 & 410 \\
\hline Total & 363 & 128 & 207 & 698 \\
\hline
\end{tabular}

Fonte: Elaborado pelo autor a partir do material da pesquisa, 2020.

Legenda:

HEpM - História e Epistemologia da Matemática.

HEnM - História para o Ensino da Matemática.

HEdM - História da Educação Matemática. 
Caracterização da História para o ensino do sistema de numeração decimal em teses e dissertações

De acordo com o levantamento inicial referente às pesquisas em História da Matemática, verificamos que, aproximadamente, 19\% foram aquelas classificadas na tendência HEpM, cujas discussões abordaram o desenvolvimento histórico-epistemológico de conceitos ou teorias, temas específicos de Matemática, relação da Matemática com outras áreas de conhecimento, aplicações da História da Matemática, desenvolvimento da História da Matemática nos livros didáticos, bem como abordagens relativas a uma subárea de conhecimento matemático e um grupo específico relativo à Matemática.

O percentual relativo às teses e às dissertações classificadas na tendência HEnM foi, aproximadamente, 22\%, cujas abordagens corresponderam a estudos e pesquisas de elaboração e testagem de métodos para o ensino de Matemática, bem como a investigações sobre as relações da Matemática com outras áreas do conhecimento em propostas de ensino de diferentes épocas, antigas e menos antigas, sobre as aplicações da História da Matemática ao ensino da disciplina, métodos de ensino de temas afins em livros didáticos antigos, de diferentes épocas, incluindo as mais recentes, desenvolvimento de produções didáticas e conceituais acerca da História para o ensino da Matemática e, também, a História da Matemática dentro das propostas didáticas que envolvem estruturas históricas (acervos, arquiteturas, produções culturais históricas, objetos culturais históricos, artefatos e instrumentos históricos).

Verificamos que foi bem expressivo o número de teses e dissertações que trataram de aspectos relativos à História da Educação Matemática. Isso se justifica, pois é um campo de investigação antigo em confronto com as demais tendências. Aproximadamente 59\% dessas pesquisas foram classificadas na tendência HEdM, pois conforme os estudos realizados por Mendes (2015), as teses e dissertações foram identificadas 
Caracterização da História para o ensino do sistema de numeração decimal em teses e dissertações

em onze subáreas, a saber: 1. Abordagem biográfica; 2. História e Memória; 3. História Oral; 4. História das Instituições; 5. História das disciplinas escolares; 6. Abordagem mista (mais de um aspecto focalizado e explorado de maneira conjugada a partir das questões de pesquisa); 7 . Investigação sobre a vida de professores de Matemática ou educadores, em suas relações com a Matemática escolar ou acadêmica (superior); 8. Investigação sobre o ensino de algum conceito ou teoria Matemática na escola; 9. Investigação sobre uma área de conhecimento; 10. Investigação sobre história de instituições; 11 . Investigação sobre o contexto cultural de uma criação (MENDES, 2014).

Com a ampliação de pesquisas sobre aspectos relativos à HEdM, identificamos outras subáreas, como:

1. Investigação sobre o ensino de Matemática em uma época determinada;

2. Investigação sobre um grupo específico de professores de Matemática;

3. Investigação sobre livros didáticos de Matemática; e

4. Investigação sobre o desenvolvimento de produções acerca da História do ensino de Matemática e História de cursos em determinadas instituições e épocas, podendo ser cursos de formação de professores.

Destacamos que a identificação dessas novas investigações ocorreu em virtude da disseminação das pesquisas desenvolvidas sobre essa tendência, a qual continuou aumentando de forma significativa nos últimos anos. Assim, foi identificado um número maior de teses e dissertações em História da Matemática. Com vista ao crescimento de teses e dis- 
Caracterização da História para o ensino do sistema de numeração decimal em teses e dissertações

sertações, apresentamos, no quadro 3, aquelas classificadas na tendência HEnM.

Quadro 3 - História para o Ensino da Matemática (1990-2018

\begin{tabular}{|c|c|c|c|}
\hline Nivel & $\begin{array}{c}\text { História da } \\
\text { Matemática }\end{array}$ & HEnM & Outros \\
\hline Doutorado & 207 & 21 & 186 \\
\hline Mestrado Acadêmico & 363 & 60 & 303 \\
\hline Mestrado Profissional & 128 & 72 & 56 \\
\hline Total & 698 & 153 & 545 \\
\hline
\end{tabular}

Fonte: Elaborado pelo autor a partir do material da pesquisa, 2020.

De acordo com os dados do quadro 3, do rol de teses e dissertações de História da Matemática produzidas no Brasil, aproximadamente $22 \%$ foram classificadas na tendência HEnM, cujas características versam sobre vários aspectos: testagem e método criado por matemático para ensinar a disciplina, aplicação de fontes históricas no ensino de Matemática, relação da Matemática com outras áreas de conhecimento, ensino de Matemática por meio de livros didáticos, desenvolvimento de conceitos e atividades históricas, atividades e artefatos históricos no ensino de Matemática, atividade didática concreta para a sala de aula, proposta de ensino em diferentes épocas, uso de conceitos matemáticos na prática do professor, propostas pedagógicas para a formação de professores e orientação didática sobre o uso de fontes históricas.

Aproximadamente $78 \%$ dos trabalhos foram agrupados na tendência "Outras", por não se enquadrarem nas mencionadas acima. De um modo geral, percebemos que o número de teses e dissertações sobre a História para o Ensino da Matemática cresceu consideravelmente. Tal resultado demonstra a importância das pesquisas desenvolvidas nessa seara, porém, ainda que esse número tenha sido significativo, existe a ne- 
Caracterização da História para o ensino do sistema de numeração decimal em teses e dissertações

cessidade de pensar novas possibilidades para manter o desenvolvimento de pesquisas inovadoras com foco no ensino a partir do uso de fontes históricas.

No quadro 4, a seguir, o agrupamento relativo as teses e dissertações que trataram da História para o Ensino de SND aos Anos Iniciais para a caracterização das propostas de atividades estabelecidas nessas produções.

Quadro 4 - História para o ensino de Sistema de Numeração Decimal (1990-2018)

\begin{tabular}{|c|c|c|c|}
\hline Nivel & HEnM & SND & Outros \\
\hline Doutorado & 21 & 5 & 16 \\
\hline Mestrado Acadêmico & 60 & 2 & 58 \\
\hline Mestrado Profissional & 72 & 2 & 70 \\
\hline Total & 153 & 9 & 144 \\
\hline
\end{tabular}

Fonte: Elaborado pelo autor a partir do material da pesquisa, 2020.

Do total de 153 teses e dissertações da HEnM, aproximadamente $6 \%$ corresponderam às teses e às dissertações com objeto de estudo na História para o Ensino de SDN aos Anos Iniciais, as quais apresentaram atividades didáticas concretas para a sala de aula, bem como orientações didáticas ao professor sobre a forma pela qual poderá utilizar fontes históricas em sala de aula e propostas pedagógicas destinadas à formação de professores. Aproximadamente 94\% foram teses e dissertações com abordagens concernentes a outros conteúdos de Matemática que, embora não sejam o foco deste estudo, serão objetos de pesquisas futuras. 
Caracterização da História para o ensino do sistema de numeração decimal em teses e dissertações

Verificamos, assim, que existe um número significativo de teses classificadas na tendência HEnM que trataram da História para o Ensino de SND. Do total de 21 teses, aproximadamente 24\% corresponderam à História para o Ensino desse conteúdo. Em relação às 60 dissertações de Mestrado acadêmico classificadas nessa tendência, aproximadamente 3\% trataram da História para o Ensino de SND aos Anos Iniciais. No que concerne às 72 dissertações do Mestrado profissional, aproximadamente $3 \%$ trataram de abordagens relativas à História para o Ensino de SND aos Anos Iniciais. Após o agrupamento das teses e dissertações que trataram do assunto em tela, realizamos a caracterização das atividades que foram elaboradas a partir do uso de fontes históricas, iniciando pela tese de Dambros (2006).

A tese intitulada "O conhecimento do desenvolvimento histórico dos conceitos matemáticos e o ensino de Matemática: possiveis relações", de Dambros (2006), orientada pela professora Maria Tereza Carneiro Soares do Programa de Pós-Graduação em Educação da Universidade Federal do Paraná, tratou das possiveis relações do conhecimento sobre o desenvolvimento histórico do SND em práticas pedagógicas de professoras dos Anos Iniciais.

Dessa maneira, foi desenvolvida uma pesquisa qualitativa de estudo de caso, em que foram realizadas entrevistas com essas professoras, a respeito de suas compreensões referentes ao desenvolvimento histórico do SND e, consequentemente, a forma como o referido conteúdo foi concebido em suas práticas durante o ensino de Aritmética. A abordagem tratada na tese foi voltada à formação de professores, no sentindo de dar subsídios à forma como o poderão utilizar fontes históricas, tomando como base o desenvolvimento histórico do SND. 
Caracterização da História para o ensino do sistema de numeração decimal em teses e dissertações

Para isso, Dambros (2006) embasa seus estudos na teoria contida nos livros História da Matemática, de Carl B. Boyer e Psicogênese e História das Ciências de Jean Piaget; apresenta, também, uma análise pontual do livro Elementos de Geometria (uma versão traduzida do livro Éléments de Géométrie, de Alexis Claude Clairaut), para explicar o desenvolvimento do conhecimento matemático enquanto conteúdo científico; para a análise das entrevistas, a autora tomou como referência os estudos de Piaget sobre as relações entre o pensamento científico e a gênese do conhecimento da criança, o qual é concebido não como algo estático, mas em contínuo desenvolvimento e, nesse aspecto, surgem paulatinamente novas habilidades na criança, que passa a adquirir informações, fazer descobertas, ganhar habilidades e notar propriedades que, outrora, não possuía preparação. No mais, a autora embasou seus estudos em Foucault, ao tratar dos conceitos arqueológico e genealógico para análise do discurso das professoras.

As atividades tratadas na tese são aquelas do livro didático utilizadas pelas professoras entrevistadas, não há atividades de cunho histórico relativas ao SND, antes, pouco ou quase nada são utilizadas as fontes históricas para abordar o tema. Percebemos que o foco da pesquisa versou sobre o conhecimento que os professores tinham a respeito de tal conteúdo numa perspectiva histórica, as discussões centraram-se na formação de professores e seus conhecimentos em relação à compreensão do desenvolvimento histórico do conteúdo em comento, bem como a forma como se deu sua evolução nos contextos socioculturais por meio das necessidades cotidianas, econômicas e políticas da humanidade ao longo da história.

As abordagens tratadas buscam incentivar o professor a ter um olhar crítico ao trabalhar com fontes históricas em sua prática pedagógi- 
Caracterização da História para o ensino do sistema de numeração decimal em teses e dissertações

ca e didática, com a perspectiva de ampliar os conhecimentos dos alunos. Olhar crítico porque é por meio de fontes históricas que os alunos podem compreender que os conhecimentos matemáticos não se constituíram linearmente, mas foram transformados, pouco a pouco, na medida em que a sociedade se reinventa.

Se o professor trabalhar no sentido de apropriar fontes históricas para enriquecer as abordagens durante sua prática, contará com ganhos em sua atuação, abrangendo, desse modo, várias possibilidades didáticas para ensinar Matemática.

A tese intitulada "Materiais Concretos, História e Ensino da Matemática: Interseções significativas para a prática pedagógica" de Pedroso (2017), orientada pela professora Silvia Fernanda de Mendonça Figueirôa, do Programa de Pós-Graduação em Ensino de Ciências e Matemática, da Universidade Estadual de Campinas, tratou sistematicamente do uso de fragmentos da História do SND, a partir da inserção da História da Matemática para professores no curso de Pedagogia, sobretudo os que trabalham na docência com alunos dos Anos Iniciais do Ensino Fundamental. Por meio de fontes históricas relativas ao conteúdo em pauta, são explorados materiais concretos, de modo a contribuir com a superação dos obstáculos epistemológicos, a partir do uso de materiais manipuláveis na formação de professores.

Para isso, utilizaram, como objeto de estudo, materiais manipuláveis e materiais concretos, com os quais trabalharam durante o processo formativo de professores no curso de Pedagogia, especialmente para professores que atuam nos Anos Iniciais do Ensino Fundamental, a fim de contribuir com a superação dos obstáculos epistemológicos em relação ao uso de materiais concretos para ensinar SND. Para a elaboração de pro- 
Caracterização da História para o ensino do sistema de numeração decimal em teses e dissertações

postas de atividades para os professores, foram utilizados alguns fragmentos históricos relativos ao SND egípcio, chinês, indiano e hinduarábico.

A tese de Pedroso (2017) tem como objetivo investigar as contribuições da inserção da História da Matemática na formação de professores, no curso de Pedagogia, com especial atenção às séries iniciais do Ensino Fundamental. Busca saber de que forma a inserção da História da Matemática na Educação pode contribuir na formação dos professores das séries iniciais, por meio do uso dos denominados materiais concretos e sua representação enquanto linguagem matemática.

O autor defende, epistemologicamente, a importância do viés sociocultural, numa perspectiva histórica, e da teoria da objetivação. Tomando como referência esses conceitos, desenvolve oficinas para professores em formação, especialmente para professores de cursos de Pedagogia e para os atuantes nos Anos Iniciais. Ao tratar sistematicamente sobre os quatro sistemas de numeração decimal criados pelas civilizações mencionadas anteriormente, foram realizadas oficinas com professores e utilizados materiais manipuláveis, bem como materiais dourados, apresentando a forma como o professor deverá abordá-los, de modo a caracterizá-los como uma proposta potente em sua prática no ensino.

As atividades desenvolvidas ao longo das oficinas trabalharam formas de representação simbólicas dos materiais concretos e manipuláveis, tendo sido elaboradas algumas propostas de atividades, durante sete encontros, no intuito de superar possiveis obstáculos epistemológicos dos professores em formação. 
Caracterização da História para o ensino do sistema de numeração decimal em teses e dissertações

Foram atividades diretamente relacionadas à formação de professores de Matemática e, para que as propostas de atividades elaboradas na tese fossem direcionadas ao ensino de Aritmética, fez-se necessária a utilização de outras fontes históricas, abordadas de maneira menos resumida, como ocorreu. É imprescindivel a utilização de variadas fontes históricas sobre o mesmo conteúdo para que as discussões sejam mais aprofundadas, sem necessidade de ulteriores readaptações, para um melhor emprego didático.

Ressaltamos que não é intenção deste estudo classificar as pesquisas como boas ou ruins, mas analisá-las com as bases teóricas e epistemológicas por nós sustentadas. Nesse sentido, apresentamos na Figura 6, a seguir, a tese de Táboas (1993), a qual busca apresentar o desenvolvimento de conceitos aritméticos a partir de aspectos culturais e o papel do homem enquanto sujeito pertencente a esse conhecimento.

A tese intitulada "O Número e sua História Cultural: Fundamento Necessário na Formação do Professor” de Táboas (1993), orientada pelo professor Newton César Balzan, no Programa de Pós-Graduação em Educação da Universidade Estadual de Campinas, tratou da evolução do conceito de número e do sistema de numeração hindu-arábico para a formação de professores. Foi feita uma análise nos livros didáticos e artigos que abordaram o conceito de número, sistema de numeração hinduarábico e uma pesquisa de observação em curso de Pedagogia.

A autora objetivou resgatar os conceitos aritméticos de número e sua representação, de forma a identificar as influências sociais e culturais na construção do conhecimento matemático, bem como reconhecer o papel do homem - sua curiosidade intelectual e seu espírito criativo - ao 
Caracterização da História para o ensino do sistema de numeração decimal em teses e dissertações

extrapolar o referido conhecimento além da fronteira do imediato (TÁBOAS, 1993).

Não há um problema de pesquisa central na tese. A autora lança um rol de questões, no intuito de compreender as dificuldades superadas historicamente pelas diferentes civilizações que contribuíram à criação do sistema de numeração hindu-arábico, a influência e a adesão do SND pela sociedade ocidental e, consequentemente, o desenvolvimento da Aritmética elementar para a criação dos números e a evolução do conceito dos números.

Analisa, ainda, livros didáticos e artigos publicados, sobre a evolução do conceito de número e do sistema de numeração hindu-arábico e, posteriormente, realiza uma pesquisa de observação nos cursos de Licenciaturas em Pedagogia nas diferentes cidades do estado de São Paulo para a coleta de materiais para, a partir de então, constatar que não existe história que remonte gradativamente à evolução do conceito de número nos livros didáticos utilizados em cursos de formação de professores, o que torna o ensino, voltado à formação de professores, compartimentar e desconectado dos aspectos histórico-culturais.

Embora a autora enfatize consistentemente a respeito do desenvolvimento do conceito de número e do sistema de numeração hinduarábico, percebemos que durante nossa análise, a tese envolveu outros sistemas de numeração que não eram seu objetivo proposto, o que denominamos de achados da pesquisa (sistema de numeração egípcio, romano, números iônicos, numerais brâmanes, numeral chinês e ático). Durante o desenvolvimento da tese, abordou a Álgebra e as quatro operações a partir de alguns fragmentos históricos, frações, operações com frações e raiz quadrada. 
Caracterização da História para o ensino do sistema de numeração decimal em teses e dissertações

A tese intitulada "Ateliês de História e Pedagogia da Matemática: contribuições para a Formação de Professores que ensinam Matemática nos Anos Iniciais", de Ferreira (2011), orientada pelo Professor Dr. Iran Abreu Mendes, do Programa de Pós-Graduação em Educação da Universidade Federal do Rio Grande do Norte, tratou do desenvolvimento de estudos relativos à História da Matemática. Teve como base o conceito mediador didático conceitual e, em seguida, por meio de uma pesquisa-ação, foram desenvolvidos ateliês com alunos das Licenciaturas de Matemática e Pedagogia, com vistas a superar as dificuldades que pairam nesses cursos.

Dessa maneira, foram elaboradas atividades e materiais didáticos baseados em informações extraídas de estudos históricos realizados por meio de ateliês sobre História e Pedagogia da Matemática, visando contribuir à formação inicial e continuada de professores que ensinam Matemática nos Anos Iniciais (FERREIRA, 2011).

Para a materialização do estudo, Ferreira (2011) lança mão de argumentos centralizadores durante o desenvolvimento da pesquisa, no sentido entender a contribuição dos Ateliês de História e Pedagogia da Matemática na formação inicial dos professores público-alvo, no intuito de propor a inclusão da História da Matemática como um recurso mediador didático e conceitual na formação de professores que atuam na rede de ensino público de Teresina.

Para tanto, a autora discutiu sobre a importância de fontes históricas para a elaboração de atividades didáticas voltadas à formação de professores, especificamente para alunos da licenciatura dos cursos já mencionados. Assim, Ferreira (2011) discutiu sobre a relação entre Edu- 
Caracterização da História para o ensino do sistema de numeração decimal em teses e dissertações

cação, Educação Matemática e formação de professores, bem como a importância do aluno como parte do processo no ensino da disciplina por meio da abstração de métodos e instrumentos que ampliem sua aprendizagem. Ademais, durante o desenvolvimento dos ateliês, alguns professores foram entrevistados e suas entrevistas foram analisadas, revelando seus depoimentos favoráveis a respeito da importância do uso, por intermédio de ateliês, da História da Matemática.

Teve como objeto de estudo um grupo de alunos dos cursos de Matemática e Pedagogia da Universidade Federal do Piauí para o desenvolvimento de cinco ateliês formativos em História e Pedagogia da Matemática. As atividades abordadas podem servir para a formação de professores e para o uso didático, pois os conteúdos tratados apresentam tal finalidade, além da elaboração de materiais didáticos que poderiam subsidiar o professor ao trabalhar o SND nos Anos Iniciais. As atividades produzidas foram sobre a origem dos números e seus significados, a multiplicação por meio da Torre de Hanói, a utilização do ábaco para desenvolver o raciocínio lógico dos alunos, o processo de contagem, entre outros aspectos.

Ferreira (2011) elaborou atividades a partir de confecções de materiais, como o ábaco, a Torre de Hanói e a Barra de Napier, a partir de fontes históricas para a representação do sistema de numeração e das quatro operações. Assim, o professor, apoiado nas atividades elaboradas na tese, poderá ter um material que manifeste a capacidade cognitiva dos alunos dos Anos Iniciais, ao se apropriar das diversas representações sobre os diversos SNDs criados pelas civilizações antigas para o ensino de Aritmética. 
Caracterização da História para o ensino do sistema de numeração decimal em teses e dissertações

A tese intitulada "Ensino de Matemática, História da Matemática e Artefatos: possibilidade de interligar saberes em cursos de formação de professores da Educação Infantil e Anos Iniciais do Ensino Fundamental" de Oliveira (2009), orientada pela Professora Bernadete Barbosa Morey do Programa de Pós-Graduação em Educação da Universidade Federal do Rio Grande do Norte, tratou do uso da História da Matemática em atividades de ensino em cursos de formação de professores da Educação Infantil e dos Anos Iniciais do Ensino Fundamental.

Os artefatos explorados foram: o Papiro de Rhind da Civilização Egípcia, a cabeça de clave do Rei Narmer, o olho de Hórus, as terras entre os rios da civilização babilônica, o tablete da civilização mesopotâmica, o Estandarte de Ur, o Códice de Dresden, a Pirâmide de Kukulcán, o calendário da Civilização Maia, o ábaco de bolso da civilização romana, dentre outros. Em cada um desses artefatos, foram apresentadas atividades de ensino exclusivamente para a formação de professores, ou seja, foram produzidas atividades que tem um caráter de contribuir para exploração dos artefatos por meio da investigação histórica a fim de trabalhar tanto os conhecimentos matemáticos, como também outras áreas de conhecimento, especificamente Arte, Português, Geografia, Ciências e História. Para isso, em cada proposta de atividade ocorreram problematizações que podem ser um caminho promissor, no sentido de integrar várias áreas de conhecimento.

As fontes históricas utilizadas na tese foram artefatos compreendidos como documentos, monumentos, imagens, fotografias que demonstram a forma como tais objetos eram retratados no passado pela humanidade em diferentes períodos históricos. Oliveira (2009, p. 31) propõe examinar a possibilidade de utilizar artefatos históricos em atividades de ensino, nos cursos de formação de professores da Educação Infantil e dos 
Caracterização da História para o ensino do sistema de numeração decimal em teses e dissertações

Anos Iniciais do Ensino Fundamental, conforme mencionamos, buscando responder a duas questões de pesquisa: "quais as possibilidades e consequências do uso de artefatos históricos em atividades de ensino, nos cursos de formação de professores para a Educação Infantil e Anos Iniciais do Ensino Fundamental? Quais potencialidades pedagógicas da História da Matemática poderão contribuir para uma melhoria do processo de ensino e aprendizagem da Matemática em cursos de formação dos professores da Educação Infantil e dos Anos Iniciais do Ensino Fundamental? ” (OLIVEIRA, 2009).

A autora trata da História da Matemática como uma metodologia de ensino e desenvolve atividades relativas aos artefatos históricos, conforme já mencionado, para o ensino de Matemática e de outras áreas de conhecimento. São múltiplos os conteúdos tratados na tese, pois suas atividades direcionam-se a uma perspectiva interdisciplinar. Embora o foco seja a Matemática, existe integração de outras áreas de conhecimento que podem ser trabalhadas por intermédio dos artefatos tratados.

As propostas trabalhadas na tese tiveram e tem contribuições significativas para a formação de professores, pois, segundo Oliveira (2009), de acordo com o resultado de sua pesquisa, as investigações acarretaram uma formação mais sólida por meio do uso dos artefatos históricos, pois percebeu a interdisciplinaridade entre Matemática, Arte, Português Geografia e História. Conforme os resultados obtidos em sua pesquisa, por meio das propostas desenvolvidas, os professores tiveram a oportunidade de conhecer a relação entre as áreas de conhecimento.

Percebemos que a tese possui propostas de atividades com potencialidades didáticas que podem ser implementadas em sala de aula. A partir de várias atividades voltadas ao ensino, o professor poderá relacio- 
Caracterização da História para o ensino do sistema de numeração decimal em teses e dissertações

nar os artefatos produzidos naquela época aos atuais, no intuito de despertar o senso crítico dos alunos e mobilizá-los à curiosidade dos porquês das transformações matemáticas ocorridas historicamente ao longo da história da humanidade a partir de suas necessidades cotidianas.

Percebemos que houve a necessidade de melhor enfatizar o conteúdo matemático durante as abordagens, pois consideramos que explorar de maneira consistente e relacional os artefatos e, consequentemente, a Matemática neles imbricada, contribuirá para uma aprendizagem com mais significado para os alunos, sobretudo porque a Matemática é bastante repudiada por muitos estudantes.

A dissertação intitulada "Ensino de Sistema de Numeração Baseado em Informações Históricas: um Estudo nos Anos Iniciais do Ensino Fundamental", da autora Silva (2017), orientada pela Professora Lucieli M. Trivizoli do Programa de Pós-Graduação para a Ciência e a Matemática da Universidade Estadual de Maringá, tratou do desenvolvimento de atividades pedagógicas em sala de aula, abordando o conteúdo de SND a partir de métodos e símbolos criados por maias e chineses. A pesquisa foi desenvolvida em uma turma com alunos do $4^{\circ}$ ano dos Anos Iniciais do Ensino Fundamental em uma Escola Municipal do Paraná.

Nela, são desenvolvidas propostas didáticas utilizando fontes históricas da Matemática e relacionando elementos do cotidiano que podem servir de mediador didático e conceitual aos professores de Matemática. Assim, para a representação do SND criado pelos maias e pelos chineses, foram utilizados os Parâmetros Curriculares Nacionais (PCNs) para sustentar seus argumentos, a respeito da relevância, para o ensino, das atividades elaboradas com base em fontes históricas. Teve como embasamento metodológico, Miguel e Miorim (2008), por evidenciar a aplicação 
Caracterização da História para o ensino do sistema de numeração decimal em teses e dissertações

de atividades a partir de três categorias de análise, relacionadas às potencialidades pedagógicas do material trabalhado pelo professor, bem como ao aluno e ao processo de ensino e aprendizagem da Matemática.

Por meio dessas três categorias, utilizou materiais manipuláveis ligados à realidade em que os alunos estão inseridos e materiais dourados para ensinar as representações numéricas pelos povos antigos mencionados anteriormente, dando significado à criação histórica de cada número. A partir dos materiais manipuláveis (pedras, gravetos, palitos e botões) e do uso de materiais dourados, utilizou a forma de representação numérica operacional desses povos e criou problemas envolvendo as quatro operações. Após ter desenvolvido as atividades, utilizou imagens de tarefas do livro didático intitulado Projeto Coopera Matemática - $4^{\circ}$ ano, PNLD 2016, para enfatizar a ausência de aspectos históricos da disciplina que geram obstáculos de aprendizagem dos números.

A dissertação possui propostas concretas para o ensino de Matemática que podem servir como apoio didático às aulas de Matemática, mais especificamente, às atividades relativas ao conteúdo do SND e, consequentemente, à formação de professores, ao desenvolver atividades utilizando fontes históricas demonstrando as representações numéricas criadas por maias e chineses. Assim, o professor que ainda não conhecesse como se deu o desenvolvimento conceitual da história do SND criado por essas civilizações encontra, nessas abordagens, fomento para superar possiveis obstáculos e refletir sobre sua prática de ensino, no sentido de desenvolver aulas que instiguem o aluno a despertar o espírito investigativo, por intermédio do uso dessas fontes históricas.

A dissertação Intitulada "História da Matemática e o Professor das Séries Iniciais: A Importância dos Estudos Históricos no Trabalho com o 
Caracterização da História para o ensino do sistema de numeração decimal em teses e dissertações

Sistema de Numeração Decimal”, Dambros (2001), orientada pela Professora Regina Flemming Damm do Programa de Pós-Graduação em Educação e Ciência da Universidade Federal de Santa Catarina, expõe, em sua dissertação, discursos de professores de diversas escolas públicas estaduais de Florianópolis sobre o ensino-aprendizagem de Matemática, História da Matemática e SND.

Para o desenvolvimento do método de pesquisa, Dambros (2001) utilizou fontes históricas sobre a história do SND indo-arábico, egípcio, romano e grego, por meio de bases teóricas de estudiosos que desenvolveram ou desenvolvem pesquisas sobre o assunto e entrevistou professores com a finalidade de identificar o grau de conhecimento referente ao assunto. Ao investigar o conhecimento dos professores sobre História da Matemática e SND, utilizou as fontes históricas como fio condutor para ampliar a aprendizagem dos alunos. Embora tenha sido apresentado o conteúdo de SND indo-arábico, não houve uma aplicação prática. Em outras palavras, para o desenvolvimento empírico em sua dissertação, a autora evidenciou apenas aspectos relativos aos depoimentos dos professores, os quais discorreram sobre suas práticas pedagógicas.

Verificamos a ausência do uso de fontes históricas, pois seria interessante, após a análise das entrevistas, que apontassem propostas didáticas que oferecessem a esses professores e aos demais interessados subsídios a suas práticas. Dambros (2001) embasou-se em Foucault, por meio do livro "Arqueologia do Saber", e em artigos oriundos da coletânea "Microfísica do poder", para empregar conceitos metodológicos como arqueologia, genealogia, verdade, discurso, formação discursiva e poder.

Após isso, centrou-se em uma análise dos discursos dos professores da rede de ensino de diversas escolas em Florianópolis. Como base 
Caracterização da História para o ensino do sistema de numeração decimal em teses e dissertações

teórica, a autora centrou seus estudos em Antônio Miguel, o qual discute sobre a importância da história na educação matemática e em Fiorentini que preconiza a História da Matemática como proposta indispensável à formação de professores. Consideramos, portanto, que as atividades da dissertação podem ser empregadas pelo professor como recurso didático para o ensino de Matemática se ele readaptar e fizer uso de outras fontes históricas que possuam as mesmas características sobre os métodos criados pelos árabes, gregos, egípcios e romanos, referentes ao Sistema de Numeração e utilizar materiais manipuláveis (pedras, palitos, materiais dourados, entre outros) para trabalhar de forma dinâmica e lúdica.

A dissertação intitulada "A evolução dos algoritmos das operações aritméticas ao longo da história", de Silva (2016), orientada pela Professora Lucia Maria Aversa Villela no Programa de Pós-Graduação em Educação Matemática da Universidade Severino Sombra, tratou do SND e de como as operações eram realizadas ao longo da história da humanidade.

Como objeto de estudo, foi feita uma abordagem sistematizada sobre o desenvolvimento a respeito dos sistemas de numeração decimal criados por várias civilizações antigas (babilônica, maia, egípcia, chinêsjaponesa, hindu-arábica) a partir de fontes secundárias de livros de autores como Ifrah, Boyer e Eves, para explicar sinteticamente sobre a forma como os vários SNDs eram concebidos pelas civilizações especificadas. Após as discussões em sua dissertação, foram elaboradas propostas de atividades com professores dos Anos Iniciais do Ensino Fundamental e alunos do Curso Normal em um colégio denominado Santa Maria.

O autor traça como objetivo "analisar a elaboração de um Componente Curricular de História da Matemática, destacando aspectos relevantes para a formação do professor de matemática e fazendo sugestões e 
Caracterização da História para o ensino do sistema de numeração decimal em teses e dissertações

recomendações metodológicas e de conteúdo" (p. 22). Silva (2016) apresenta dois problemas de pesquisa: o que a História da Matemática pode acrescentar à prática profissional dos docentes, sobre o ensino das operações fundamentais e o que podemos aprender com o ensino dos sistemas de numeração de culturas diferentes e seu desenvolvimento e como utilizaremos esses conhecimentos adquiridos na pesquisa, colocando em prática no dia a dia do professor.

Silva (2016) cita alguns autores em seu trabalho, mas não foram explorados os conceitos para sustentação de seus argumentos e do objeto de estudo tratado. Dessa maneira, percebemos a ausência de conceitos para sustentar os argumentos. Outro ponto que merece destaque, embora não seja nosso enfoque nesse estudo, mas, considerando que o autor busca tratar da História da Matemática como uma metodologia de ensino, é a ausência de referenciais teóricos nesse sentido.

Assim, verificamos que houve certa dificuldade em estabelecer argumentos que possibilitem o leitor compreender que tipo de metodologia foi discutida no texto para a geração de um ensino que efetivamente contribua à melhoria da prática pedagógica do professor que ensina Matemática.

A dissertação intitulada "História da Matemática na Formação de Professores: Sistemas de Numeração Antigos" de Silva (2016), orientado pela Professora Bernadete Barbosa Morey, do programa de PósGraduação em Ensino de Ciências Naturais e Matemática da Universidade Federal do Rio Grande do Norte, tratou dos sistemas de numeração antigos dos egípcios, maias e babilônicos. Assim, foram apresentadas fontes históricas para a elaboração de atividades didáticas para os professores em formação. 
Caracterização da História para o ensino do sistema de numeração decimal em teses e dissertações

Dessa maneira, para que sejam utilizadas no ensino de Matemática, é necessário passar pelo processo de readaptação e criar outras sugestões didáticas com características investigativas para que sejam empreendidas em sala de aula, de modo que os alunos possam desenvolver pesquisas a partir do uso da investigação histórica e do professor mediador do processo. Silva (2016) apresenta como objetivo descrever uma proposta de inserção da História da Matemática na formação de professores. São elaboradas atividades a partir do uso de simbolos dos sistemas de numeração das civilizações antigas, ou seja, o significado numérico atribuído a cada simbolo e atividades algorítmicas envolvendo as quatro operações aritméticas.

O autor trabalhou com três tipos de sistemas de numeração antigos a partir de três oficinas com alunos no curso de Licenciatura em Matemática, as quais envolveram agrupamentos, jogos e as quatro operações. A partir da oficina foi apresentado um produto educacional com várias atividades que podem servir ao trabalho com crianças dos Anos Iniciais, desde que sejam feitas readaptações, pois, o objetivo proposto foi no sentido de trabalhar com alunos de Graduação e professores em formação e as atividades foram similares àquelas constantes no livro didático, com diferenças apenas na troca dos números pelos símbolos utilizados nas civilizações antigas.

\section{Reflexões Finais}

Por meio do levantamento das produções em História da Matemática, bem como um estudo pormenorizado que foi realizado com teses de doutorado e dissertações de mestrados acadêmico e profissional, que trataram da história para o ensino do sistema de numeração decimal, con- 
Caracterização da História para o ensino do sistema de numeração decimal em teses e dissertações

cluímos que há poucos trabalhos publicados do banco de dados da CAPES e a necessidade de que se produza mais trabalhos com essa temática, visto que as diferentes representações numéricas propiciam um ambiente de aprendizagem favorável ao aluno, principalmente aqueles dos anos iniciais que se deparam formalmente com os números.

O conhecimento base sobre numeração deve ser concretizado e efetivamente explorado pelos professores, para que, quando chegar ao nivel mais exigido para o aluno, os obstáculos de aprendizagem em relação aos conteúdos mais avançados sejam superados. Para além disso, embora admitimos que, por meio do levantamento percebemos a necessidade de se produzir mais trabalhos sobre sistema de numeração decimal, as produções das quais foram analisadas, podem servir como apoio didático pelo professor, pois com base na caracterização das produções acadêmicas que foram realizadas, é possivel ao professor lançar mãos das fontes históricas e propostas de atividades didáticas que foram elaboradas para os anos finais do Ensino Fundamental, e, por assim ser,as caracterizações realizadas em cada trabalho podem ser utilizadas na sala de aula pelo professor, com vistas a tornar suas aulas mais significativas.

Os resultados de nossa pesquisa sinalizaram sobre a importância das produções que tratam do sistema de numeração decimal com potencialidade didática para o ensino de matemática, as quais são indispensáveis e determinantes para a socialização do conhecimento matemático. Outro aspecto que deve ser mencionado a partir do estudo realizado é a classificação dessas produções que pode ser objeto de novos estudos e investigação para os interessados, especialmente se tratando de outras tendências mencionadas anteriormente. Portanto, o estudo realizado traz contribuições significativas para o campo da Educação Matemática e podem servir como lócus de investigações futuras. 
Caracterização da História para o ensino do sistema de numeração decimal em teses e dissertações

\section{Referências}

BARROS, Rafael José Alves do Rego; MENDES, Iran Abreu. Dissertações e teses em História e Epistemologia da Matemática: contribuições para a abordagem da Geometria Espacial no Ensino Médio. Principia, n. 37, p. 139-150, nov. 2017.

DAMBROS, Adriana Aparecida. História da Matemática e o Professor das Séries Iniciais: A Importância dos Estudos Históricos no Trabalho com o Sistema de Numeração Decimal. 2001. 271 f. Dissertação (Mestrado em Educação e Ciência) - Educação e Ciência, Universidade Federal de Santa Catarina, Florianópolis, 2001.

DAMBROS, Adriana Aparecida. O conhecimento do desenvolvimento histórico dos conceitos matemáticos e ensino de Matemática: possiveis relações. 2006. 193 f. Tese (Doutorado em Educação) - Setor de Educação, Universidade Federal do Paraná, Curitiba, 2006.

FERREIRA, Lúcia Helena Bezerra. Ateliês de História e Pedagogia da Matemática: contribuições para a formação de professores que ensinam Matemática nos Anos Iniciais. 2011. 216 f. Tese (Doutorado em Educação) - Centro de Ciências Sociais Aplicadas, Universidade Federal do Rio Grande do Norte, Natal, 2011.

GAMBOA, Silvio Sánchez. Pesquisa em educação: métodos e epistemologias. 2. ed. Chapecó: Argos, 2012.

MENDES, Iran Abreu. Uma história das pesquisas em História da Matemática no Brasil: produções, disseminações e contribuições à Formação de Professores de Matemática. Universidade Federal do Pará: Projeto de pesquisa. Belém, 2018a.

MENDES, Iran Abreu. História para o Ensino de Matemática na Formação de Professores e na Educação Básica: uma análise da produção brasileira (1997-2017). UFPA: Projeto de pesquisa. Belém, 2018b.

MENDES, Iran Abreu. Cartografias da produção em História da Matemática no Brasil: um estudo centrado nas dissertações e teses defendidas entre 19902010. Relatório de Pesquisa (Bolsa produtividade CNPq). Universidade Federal do Rio Grande do Norte, Natal, 2014. 
Caracterização da História para o ensino do sistema de numeração decimal em teses e dissertações

MENDES, Iran Abreu. História da Matemática no Ensino: entre trajetórias profissionais, epistemologias e pesquisas. São Paulo: Ed. Livraria da Física, 2015.

MENDES, Iran Abreu. História para a Educação Matemática: apontamentos sobre as pesquisas brasileiras. Exitus, v. 9, n. 2, p. 26-50, jun., 2019.

MENDES, Iran Abreu. História para o ensino da Matemática: uma reinvenção didática para a sala de aula. Cocar. Edição Especial, n. 3, p. 145-166, jul. 2017.

MENDES, Iran Abreu; SILVA, Carlos Aldemir Farias. Problematization and Research as a Method of Teaching Mathematics. IEJME, v. 13, n. 2, p. 41-55, abr. 2018.

MIGUEL, Antonio; MIORIM, Ângela Maria. História da Educação Matemática: Propostas e desafios. 1. ed., 2 reimp. Belo Horizonte: Autêntica, 2008.

OLIVEIRA, Rosalba Lopes de. Ensino de Matemática, História da Matemática e artefatos: possibilidade de interligar saberes em cursos de formação de professores da Educação Infantil e Anos Iniciais do Ensino Fundamental. 2009. 218f. Tese (Doutorado em Educação) - Centro de Ciências Sociais Aplicadas, Universidade Federal do Rio Grande do Norte, Natal, 2009.

PEDROSO, André Pereira. Materiais concretos, história e ensino da Matemática: interseções significativas para a prática pedagógica. 2017. 227 f. Tese (Doutorado em Ensino de Ciências e Matemática) - Pós-Graduação em Ensino de Ciências e Matemática, Universidade Estadual de Campinas, Campinas, 2017.

PIRES, Lucas Silva. História para o Ensino de Sistema de Numeração Decimal em Teses e Dissertações (1990-2018). REMATEC, a. 14, n. 32, p.193-211, dez. 2019.

PIRES, Lucas Silva; MENDES, Iran Abreu. História da Matemática do Ensino Fundamental nos Livros de Minicursos da SBHMAT (2001-2017). Revista Prática Docente. v. 5, n. 1, p. 28-44, jan/abr., 2020.

SAD, Lígia Arantes (Ed.). Anais do VI Seminário Nacional de História da Matemática. Rio Claro: SBHMat, 2005. 
Caracterização da História para o ensino do sistema de numeração decimal em teses e dissertações

SILVA, Alexandre Oliveira. A evolução dos algoritmos das operações aritméticas ao longo da história. 2016. 104f. Dissertação (Mestrado Profissional em Educação Matemática) - Pró-Reitoria de Pesquisa e Pós-graduação, Universidade Severino Sombra, Vassouras, 2016.

SILVA, Eliane Siviero da. Ensino de sistemas de numeração baseado em informações históricas: um estudo nos Anos Iniciais do Ensino Fundamental. 2017. 149 f. Dissertação (Mestrado em Educação para a Ciência e a Matemática) - Centro de Ciências Exatas, Universidade Estadual de Maringá, Maringá, 2017.

SILVA, Gesivaldo dos Santos. História da Matemática na formação de professores: sistemas de numeração antigos. 2016. 80f. Dissertação (Mestrado Profissional em Ensino de Ciências Naturais e Matemática) - Centro de Ciências Exatas e da Terra, Universidade Federal do Rio Grande do Norte, Natal, 2016.

TÁBOAS, Carmen Maria Guacelli. O número e sua história cultural fundamento necessário na formação do professor. 1993. 233f. Tese (Doutorado) Pós-Graduação em Educação, Universidade Estadual de Campinas, Campinas, 1993. 